\title{
Genetic diversity and geographic structure in Aglaia elaeagnoidea (Meliaceae, Sapindales), a morphologically complex tree species, near the two extremes of its distribution
}

\author{
A.N. Muellner ${ }^{1}$, H. Greger ${ }^{2}$, C.M. Pannell ${ }^{3}$
}

Key words

Aglaia

biogeography

dispersal

internal transcribed spacer (ITS)

Meliaceae

molecular clock

Sapindales

\begin{abstract}
Aglaia elaeagnoidea is the most widespread and one of the more morphologically diverse complex species in the largest genus of the mahogany family (Meliaceae, Sapindales). We performed maximum parsimony, maximum likelihood and Bayesian analyses (nuclear ITS rDNA) to estimate genetic relations among samples of $A g l a i a$ elaeagnoidea, and their phylogenetic position within Aglaia (more than 120 species in Indomalesia, Australasia, and the Pacific islands). Based on 90 accessions of Melioideae (ingroup) and four taxa of Cedreloideae (outgroup), this study 1) provides a first assessment of the genetic diversity of Aglaia elaeagnoidea; 2) investigates the geographic structure of the data in selected eastern and western regions of its distribution; and 3) suggests that Australia has been colonized only recently by $A$. elaeagnoidea and other species within the genus (Miocene/Pliocene boundary to Pliocene). Based on DNA data, morphology and additional evidence derived from biogenetic trends (secondary metabolites), the name Aglaia roxburghiana could be reinstated for specimens from the western end (India, Sri Lanka), but we have no data yet to indicate definitely where $A$. roxburghiana ends and $A$. elaeagnoidea begins either morphologically or geographically. Viewed in a more general context, Aglaieae are an ideal model group for obtaining more insights into the origin and evolution of Indomalesian and Australian biotas.
\end{abstract}

Published on 30 October 2009

\section{INTRODUCTION}

The genus Aglaia Lour. presents an example for a group of plants in which species delimitation has been a major challenge to botanists (Pannell 1992). Aglaia is the largest genus of the predominantly subtropical and tropical angiosperm family Meliaceae (mahogany family, order Sapindales). It comprises at least 120 arborescent species and presents more taxonomic problems in species delimitation than any other genus of the family (Pannell 1992, 1995, 1998a, b, 2004, Muellner 2008, Muellner et al. 2005, 2008a). Aglaia forms an important component of the moist tropical forest in the Indomalesian region. The total distribution range comprises the tropics of Southeast Asia from Sri Lanka and India to Australia (Queensland, Northern Territory, and Western Australia) and as far east as the island of Samoa in Polynesia and north to the Mariana (Saipan, Roti, and Guam) and Caroline Islands (Palau and Ponape) in Micronesia (Pannell 1992)

In the most recent taxonomic treatment of the whole genus, Pannell (1992, 1998a, b) adopted a wide species concept. For many species even the most indicative morphological characters, such as indumentum, fruit, and floral morphology, show considerable variation. Pannell (1992) recognized different types of species. 'Isolated species' are morphologically distinct and with either a small (e.g., A. coriacea Korth. ex Miq.) or extensive (e.g., A. cucullata (Roxb.) Pellegr.) geographical distribution. In contrast, members of morphologically closely resembling pairs or larger groups of species are often separable

\footnotetext{
Grunelius-Moellgaard Laboratory, Department of Botany and Molecular Evolution, Senckenberg Research Institute, Senckenberganlage 25, D-60325 Frankfurt, Germany.

${ }^{2}$ Comparative and Ecological Phytochemistry, Faculty Center of Botany, University of Vienna, Rennweg 14, A-1030 Vienna, Austria.

${ }^{3}$ Department of Plant Sciences, University of Oxford, South Parks Road, Oxford OX1 3RA, United Kingdom.
}

only by using the combined variation of several overlapping characters (Pannell 1992). Members of these groups may be allopatric (e.g., A. elliptica Blume and $A$. cinnamomea Baker f.; Pannell 1993) or sympatric (e.g., $A$. korthalsii Miq. and $A$. speciosa Blume). In 'variable species' variation is relatively simple, usually involving two variants linked by intermediates. 'Complex species' have a more extensive, complicated, and putatively reticulate pattern of variation, for which extremes appear at first sight to belong to distinct species (Pannell 1992, 1998a, b).

Muellner et al. (2005) provided the first evaluation of these taxonomic concepts with data independent of morphology. Their study based on maximum parsimony and Bayesian analyses of nuclear ITS and plastid rps16 intron, as well as comparison of chemical profiles observed by means of high performance liquid chromatography (HPLC) and gas chromatography coupled to mass spectrometry (GC-MS), indicated that variable and complex species were more heterogeneous, i.e., probably containing more than one taxon each, than taxonomically isolated species (Muellner et al. 2005).

We performed maximum parsimony (MP), maximum likelihood $(\mathrm{ML})$ and Bayesian analyses of sequence data from the internal transcribed spacers (ITS) of nuclear ribosomal DNA (nrDNA), defined as the unit containing the ITS1 spacer, 5.8S rRNA gene, and ITS2 spacer, to estimate genetic relationships within one of the morphologically complex and geographically most widely distributed species of the genus, Aglaia elaeagnoidea (A.Juss.) Benth. The aims of our study were to 1) provide a first assessment of the genetic diversity of $A$. elaeagnoidea by sampling near the two extremes of its distribution range; 2 ) investigate the geographic structure of the data over the sampled geographic range; and 3) infer the geographic and temporal origin of selected clades within Aglaia. The DNA data are compared to chemical profiles of the respective specimens to investigate if phylogenetic relationships are reflected by biogenetic trends. 
Table 1 Voucher information and GenBank accession numbers for samples used in this study (in alphabetical order). Voucher specimens are deposited in the following herbaria: FHO = Daubeny Herbarium, University of Oxford; FR = Herbarium Senckenbergianum, Senckenberg Research Institute; K = Royal Botanic Gardens Kew; KEP FRI = Forestry Institute Malaysia; KYGH = Kyoto Takeda Herbal Garden; NCU = University of North Carolina; WU = University of Vienna.

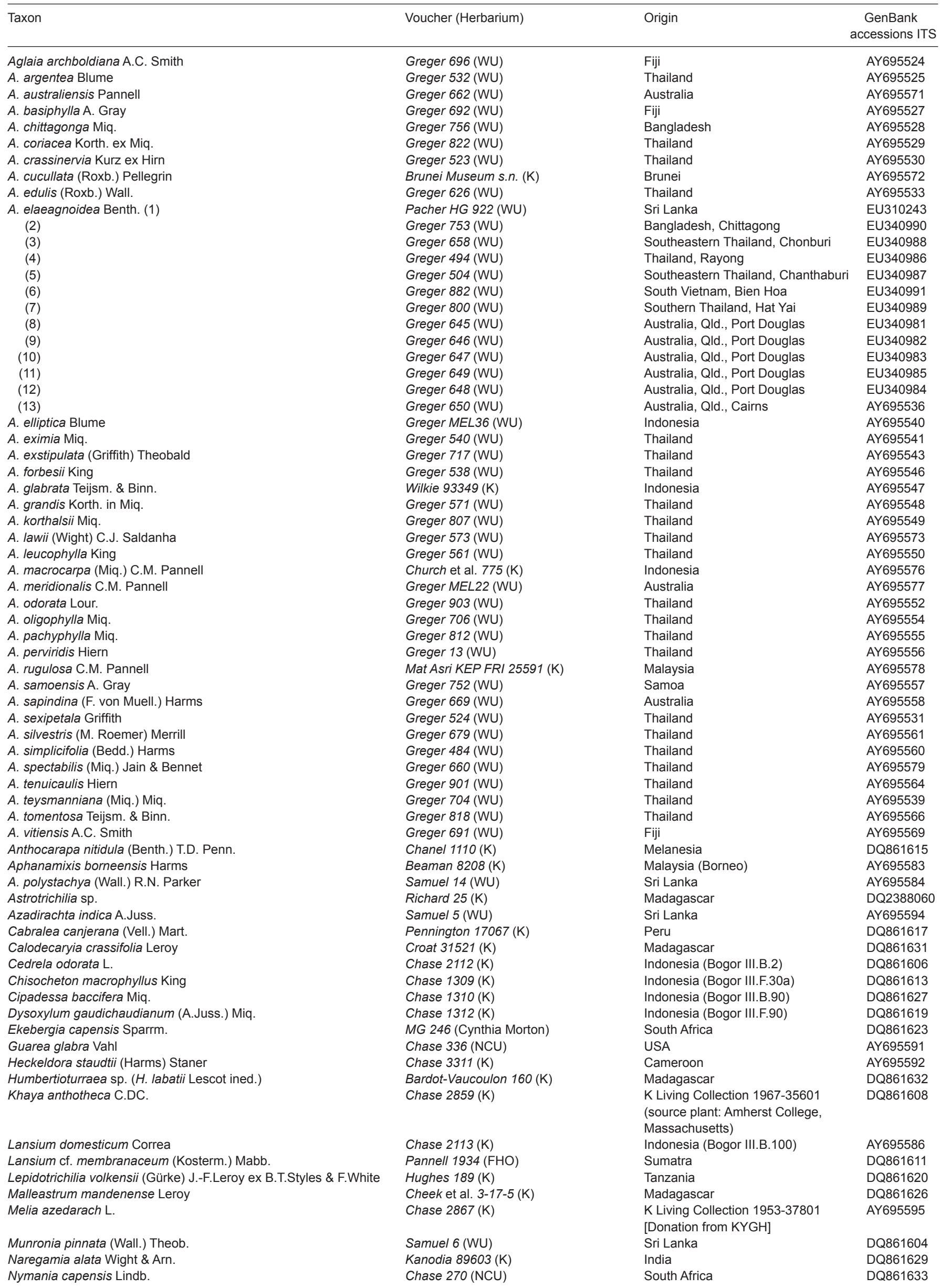


Table 1 (cont.)

\begin{tabular}{|c|c|c|c|}
\hline Taxon & Voucher (Herbarium) & Origin & $\begin{array}{c}\text { GenBank } \\
\text { accessions ITS }\end{array}$ \\
\hline Owenia vernicosa F. Muell. & Evans $M 3071$ & Australia & DQ861622 \\
\hline Pseudobersama mosambicensis (Sim) Verdc. & Bidgood, Abdallah \& Vollesen $1426(\mathrm{~K})$ & Tanzania & DQ238064 \\
\hline 'Pseudocarapa nitidula' (Benth.) T.D.Penn. & Chase $3313(\mathrm{~K})$ & Australia & DQ861616 \\
\hline Pseudoclausena chrysogyne (Miq.) T.P.Clark & Muellner 2052 (FR) & Malaysia (FRIM Arboretum) & DQ861602 \\
\hline Pterorhachis zenkeri Harms & Breteler $2741(\mathrm{~K})$ & Cameroon & DQ861628 \\
\hline Quivisianthe papinae Baill. & Phillipson 1650 (K) & Madagascar & DQ861605 \\
\hline R. humile (Hassk.) Mabb. & Trichon VT 641 (FHO) & Sumatra & DQ861612 \\
\hline R. kinabaluense (Kosterm.) Mabb. & $A L F B \quad 112 / 87(\mathrm{~K})$ & Malaysia (Borneo) & AY695589 \\
\hline R. kostermansii (Prijanto) Mabb. & Kostermans $19215(\mathrm{~K})$ & Indonesia (W Sumbawa) & DQ861634 \\
\hline Ruagea pubescens Karst. & Pennington \& Frere $13761(\mathrm{~K})$ & Ecuador & AY695593 \\
\hline Sandoricum borneense Miq. & Chase $1313(\mathrm{~K})$ & Indonesia (Bogor III.B.92) & DQ861601 \\
\hline Sphaerosacme decandra (Wal.) T.D.Penn. & Williams \& Stainton $8533(\mathrm{~K})$ & Ecuador & AY 695590 \\
\hline Swietenia macrophylla King & Chase 250 (NCU) & USA & DQ861609 \\
\hline Synoum glandulosum (Sm.) A.Juss. & Schodde $5101(\mathrm{~K})$ & Australia & DQ861618 \\
\hline Toona sp. & Terrazas s.n. (K) & Australia & DQ861607 \\
\hline T. prieureana A.Juss. & Neumann 1518 (FR) & West Africa & EF136576 \\
\hline Turraea sericea Sm. & Civeyrel $1336(\mathrm{~K})$ & Madagascar & DQ861630 \\
\hline T. heterophylla Sm. & Küppers 2212 (FR) & West Africa & EF136578 \\
\hline Turraeanthus sp. & Carvalho 4348-1 (K) & Equat. Guinea & DQ861614 \\
\hline Vavaea amicorum Benth. & Katik et al. $74722(\mathrm{~K})$ & Papua New Guinea & DQ861610 \\
\hline Walsura tubulata Hiern & Chase $1314(\mathrm{~K})$ & Indonesia (Bogor VIII.B.127) & DQ861625. \\
\hline
\end{tabular}

The ITS region was the DNA marker of choice since previous analyses of plastid rbcL, matK, and nuclear 26S rDNA did not provide sufficient phylogenetic information for Melioideae (compare Muellner et al. 2003, 2006), and screening with other plastid markers (e.g. rps16 intron, IGS atpB-rbcL, trnL intron and IGS trnL-trnF) did not exhibit a sufficient amount of informative sites. In addition, single copy nuclear genes, in contrast to ITS, are at present technically demanding to sequence and generally not retrievable from herbarium samples, because their amplification is highly subject to DNA quality (Cowan et al. 2006). This is especially true for tropical plants with high amounts of bioactive and/or PCR-inhibitory compounds, like the Meliaceae (A.N. Muellner pers. obs.).

\section{MATERIAL AND METHODS}

We analyzed ITS data of 90 accessions of Melioideae, including representatives and type species of all three currently recognized sections within Aglaia (Amoora, Neoaglaia, and Aglaia), 13 accessions of $A$. elaeagnoidea from different locations of its distribution range (Fig. 1), and four accessions of Cedreloideae as outgroup taxa (Table 1). Broadscale intrafamilial phylogenetic relationships of Meliaceae were previously assessed using DNA sequence data from three regions: plastid genes $r b c \mathrm{~L}$, matK, and nuclear 26S rDNA (Muellner et al. 2003, 2006). Phylogenetic relationships within Melioideae have recently been assessed using nuclear ribosomal DNA sequence data (Muellner et al. 2008b).

\section{Plant material}

Material of Aglaia elaeagnoidea was collected during excursions to Sri Lanka, Bangladesh, Thailand, Vietnam and Australia. Herbarium vouchers of this species are deposited at WU; herbarium specimens of the other Meliaceae are deposited at FHO, FR, FRIM, K, NCU, and WU (Table 1). ITS sequences of 35 taxa of Aglaia (other than A. elaeagnoidea) and 46 other taxa were available from the first authors' previous work on $\mathrm{Me}$ liaceae (Muellner et al. 2005, 2008b). Besides 48 accessions of Aglaia, our ITS matrices also include representatives of all other genera of tribe Aglaieae (Lansium Corrêa, Reinwardtiodendron Koord., Aphanamixis Blume, Sphaerosacme Wall. ex Royle), plus representatives of all other tribes of Melioideae.

\section{Isolation of DNA, amplification, and sequencing}

Total DNA from leaf fragments was extracted using a NucleoSpin Plant kit (Macherey-Nagel, Dueren, Germany). PCR amplification was carried out using the primers in Muellner et al. (2005). A 50- $\mu \mathrm{L}$ reaction mix contained $24.6 \mu$ sterile $\mathrm{ddH}_{2} 0$, $5 \mu \mathrm{l} 10 \times$ reaction buffer $Y$ (peqlab, Erlangen, Germany), $2.4 \mu \mathrm{l}$ $\mathrm{MgCl}_{2}(25 \mathrm{mM}), 1 \mu \mathrm{l}$ peqGold Taq Polymerase (5 U/ $\left.\mu \mathrm{l}\right), 0.5 \mu \mathrm{l}$ of the primers each (10 pmol; biomers.net, Ulm, Germany), $8 \mu \mathrm{ldNTP} \operatorname{mix}(2.5 \mathrm{mM}$; Carl Roth, Karlsruhe, Germany), $5 \mu \mathrm{l}$ template DNA (c. 25-50 ng/ $\mathrm{\mu l}$ ), $1 \mu \mathrm{l}$ BSA (1x; New England Biolabs, Frankfurt, Germany), as well as $2 \mu \mathrm{L}$ DMSO (dimethyl sulfoxide; Stratagene Europe, Amsterdam, Netherlands) to stabilize the enzyme, reduce secondary structure problems, favour precise annealing, and prevent preferential amplification of pseudogenes. Amplifications were carried out using the programme of Muellner et al. (2005). PCR products were cleaned using a NucleoSpin Extract II kit (Macherey-Nagel, Dueren, Germany). The same primers as cited above were used for sequencing. Sequencing reactions were run on a CEQTM 8800 Genetic Analysis System (Beckman Coulter, Krefeld, Germany), following the manufacturer's protocols.

\section{Sequence editing and alignment}

Editing and assembly of the complementary strands were carried out with SeqManTM II v5.07 (Lasergene, DNASTAR, Inc., Madison, WI, USA). ITS sequences were explored for the presence of several structural motifs: the conserved angiosperm motif GGCRY - (4 to 7 n) - GYGYCAAGGAA (Liu \& Schardl 1994); the conserved (C1-C6) and variable (V1-V6) domains determined for plant ITS2 sequences (Hershkovitz \& Zimmer 1996); and the conserved angiosperm motif $5^{\prime}$-GAATTGCAGAATCC-3' within the 5.8S rDNA gene (Jobes \& Thien 1997). Folding predictions of secondary structures of the ITS1 and ITS2 RNA transcripts were made at the M. Zuker web server (http://www.bioinfo.rpi.edu/zukerm/) by use of the mfold program v3.1 (Mathews et al. 1999, Zuker et al. 1999). Foldings were conducted at $37^{\circ} \mathrm{C}$. After a first rough alignment with CLUSTAL version X (Thompson et al. 1997), corrections were made manually by using secondary structure predictions of ITS1 and ITS2 RNA transcripts as a guide for alignment across genera. Secondary structure predictions were confirmed by hemi-compensatory base changes and full compensatory base 


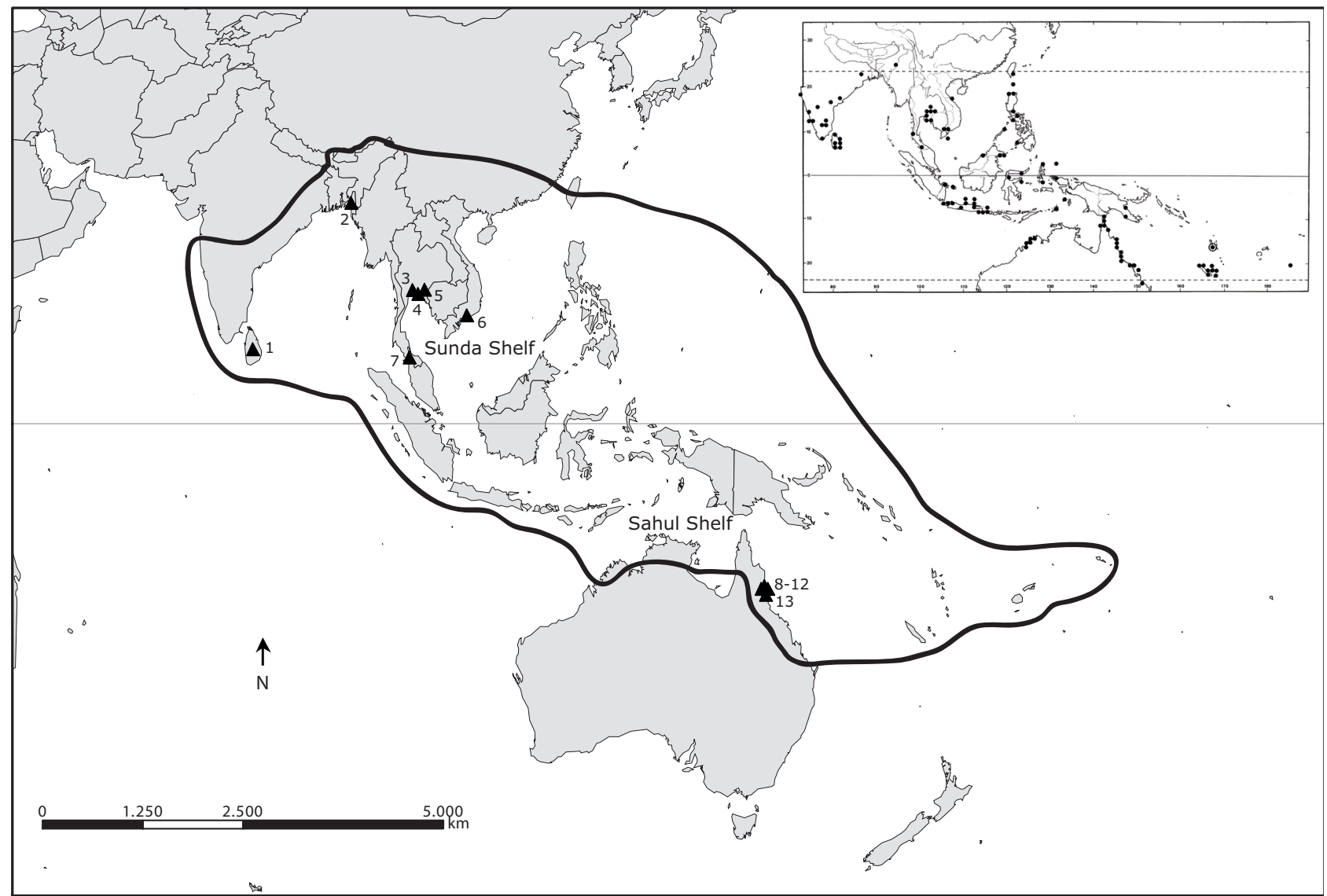

Fig. 1 Locations and number designation of specimens sampled, and total distribution of Aglaia elaeagnoidea (small map on the right: after Pannell 1992). Outer line delimits the geographical distribution of the tribe Aglaieae.

changes that preserved the predicted folding pattern. A total of 803 aligned positions were included in the matrices for phylogenetic analyses of ITS (including ITS1, 5.8S rDNA, and ITS2). Gaps were coded as missing data. Aligned matrices are available from the first author (alexandra.muellner@senckenberg. de); new sequences have been deposited in GenBank under the accession numbers EU340981-EU340991 (http://www. ncbi.nlm.nih.gov/).

\section{Phylogenetic analyses}

MP analyses of the ITS dataset were performed using PAUP* v4.0b10 (Swofford 2002). Substitutions at each nucleotide position were treated as independent, unordered, multi-state characters of equal weight (Fitch parsimony, Fitch 1971). Heuristic searches were performed using 1000 random additions of taxa, tree bisection-reconnection (TBR) branch swapping, and the option MulTrees (keeping multiple, shortest trees), but holding only 10 trees per replicate to reduce time spent in swapping on large numbers of trees. After 1000 replicates, we then used the shortest trees found as starting trees for a swapping-to-completion search (but with a tree limit of 15000 ). Robustness of clades was estimated using bootstrapping (Felsenstein 1985) with 1000 replicates, using simple sequence addition, TBR branch swapping, and MulTrees, again holding 10 trees per replicate. We consider $75-84 \%$ bootstrap values moderate support and $85-100 \%$ strong support.

$\mathrm{ML}$ analyses were performed with RAxML v2.2.1 (Stamatakis 2006, http://icwww.epfl.ch/ stamatak/index-Dateien/Page443. $\mathrm{htm}$ ), and Bayesian analyses with MrBayes v3.1.2 (Ronquist \& Huelsenbeck 2003, http://mrbayes.csit.fsu.edu/). The substitution models employed in these analyses were found using Modeltest v3.06 (Posada \& Crandall 1998, http://darwin.uvigo. es/software/modeltest.html), which indicated the general time reversible model as best fitting our data with a proportion of invariable sites and a gamma shape parameter alpha to model rate heterogeneity $(G T R+I+G)$. For the Bayesian analyses, model parameters were estimated directly during two parallel runs, using four simultaneous chains and two million cycles each, sampling one tree every 100 generations. Trees that preceded stabilisation of the likelihood value were excluded, and the remaining trees were used to calculate posterior probabilities via the construction of a majority rule consensus tree in PAUP. For the ML searches with RAxML we employed the GTR + G model, using 25 rate categories (instead of four as used in the Bayesian analyses).

\section{Divergence time estimation}

A likelihood-ratio test (LRT) rejected the null hypothesis of rate constancy for ITS. We therefore employed non-parametric rate smoothing (NPRS; Sanderson 1997) as implemented in TreeEdit v1.0-a4.61 (Rambaut \& Charleston 2000) and a relaxed Bayesian clock approach as implemented in the 'multidivtime' program of Thorne \& Kishino (2002, http://statgen. ncsu.edu/thorne/).

The input topology for the time estimation was the ITS ML tree. Parameter values in 'multidivtime' were estimated with PAML's baseml v3.14 (Yang 1997). The program 'estbranches' (Thorne et al. 1998) was then used to calculate branch lengths and their variance, given the sequence data (94 ITS sequences of a length of $803 \mathrm{nt}$ ), the model parameter values from PAML, and the specified rooted topology. Branch lengths from 'estbranches' became the priors for mcmc searches in 'multidivtime' (Thorne \& Kishino 2002) that sought to find the most likely model of rate change (with rate change assumed to be log-normally distributed), given the topology, time constraints on nodes (below), and a Brownian motion parameter ( $v$ that 


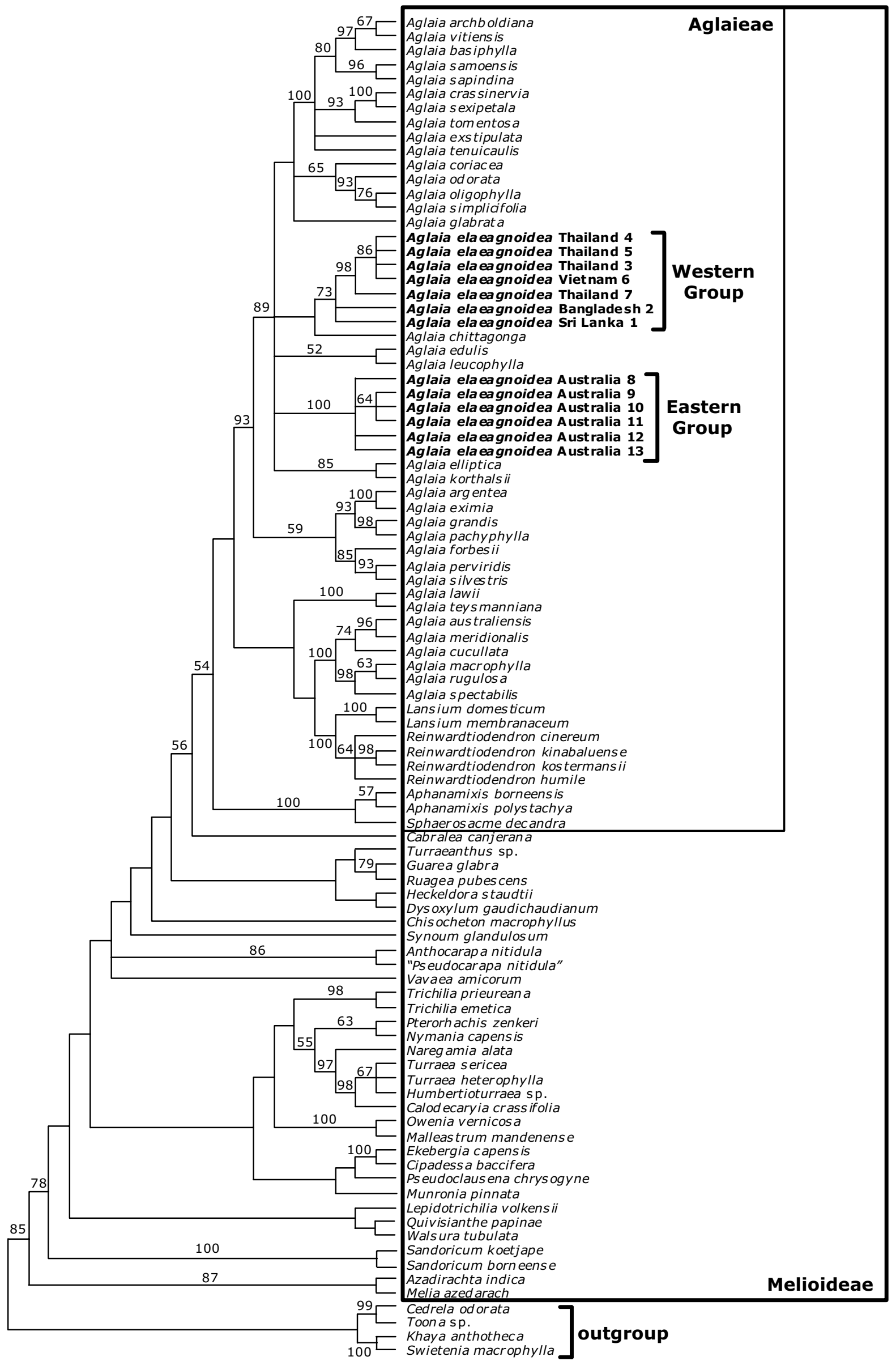

Fig. 2 Strict consensus tree of 288 trees obtained from the maximum parsimony analysis of the ITS dataset of 94 Meliaceae accessions. Numbers are bootstrap percentages (1 000 replicates). 
Fig. 3 Bayesian tree (20 000 total trees, burn-in of 910 trees) of the ITS dataset of 94 Meliaceae accessions, upper part (Aglaieae). Numbers are Bayesian posterior probabilities. Divergence time estimates derived from a Bayesian relaxed clock (Thorne \& Kishino 2002) and a nonparametric rate smoothing approach (NPRS: Sanderson 1997) are given in million years ago (Ma) and are marked by arrows.

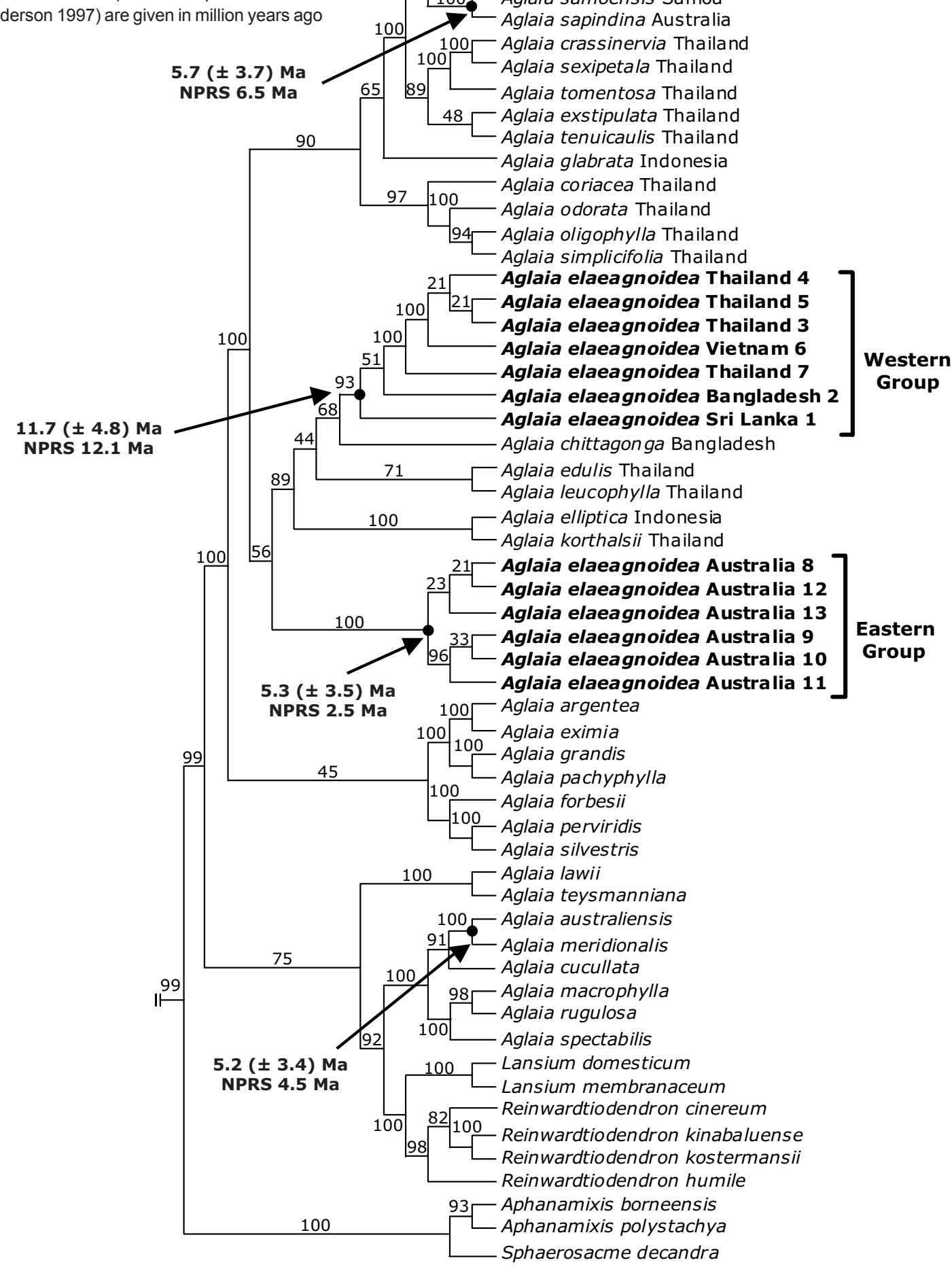

controls the magnitude of autocorrelation per million years (Myr) along the descending branches of the tree. Prior gamma distributions on parameters of the relaxed clock model were as follows (following the 'multidivtime' manual for setting the mean and SD; http://statgen.ncsu.edu/thorne/multidivtime.html): the mean and SD of the prior distribution for the root age were set to 75 Myr based on fossils (below) and previous studies of Muellner et al. (2006, 2007, 2008a). The mean and SD of the prior distribution for the ingroup root rate were set to 0.0024 substitutions/site/Myr by dividing the median of the distances between the ingroup root and the tips by $75 \mathrm{Myr}$. The prior and SD for $v$ were set to 0.013 , following the recommendation of Thorne's manual that the time between root and tips multiplied by $v$ be about 1 . Markov chains in 'multidivtime' were run for 1 million generations, sampling every 100 th generation for a total of 10000 trees, with a burn-in of 10000 generations before the first sampling of the Markov chain.

\section{Constraints and calibrations}

Absolute time estimates in the Bayesian approach were obtained by simultaneously constraining four nodes (numbered 1-4 below); for the NPRS clock we constrained one node (numbered 5 below).

1. The root node of our dataset (i.e., the most recent common ancestor of Melioideae and Cedreloideae) was constrained to maximally 137 million years ago (Ma), based on the onset of angiosperm radiation (Hughes 1994, Brenner 1996). 
Fig. 4 Maximum likelihood tree from the analysis of the ITS dataset of 94 Meliaceae accessions, upper part (Aglaieae). Numbers are bootstrap percentages (1 000 replicates). Secondary metabolites of Aglaia elaeagnoidea after Brem (2002) and Hofer (2002).

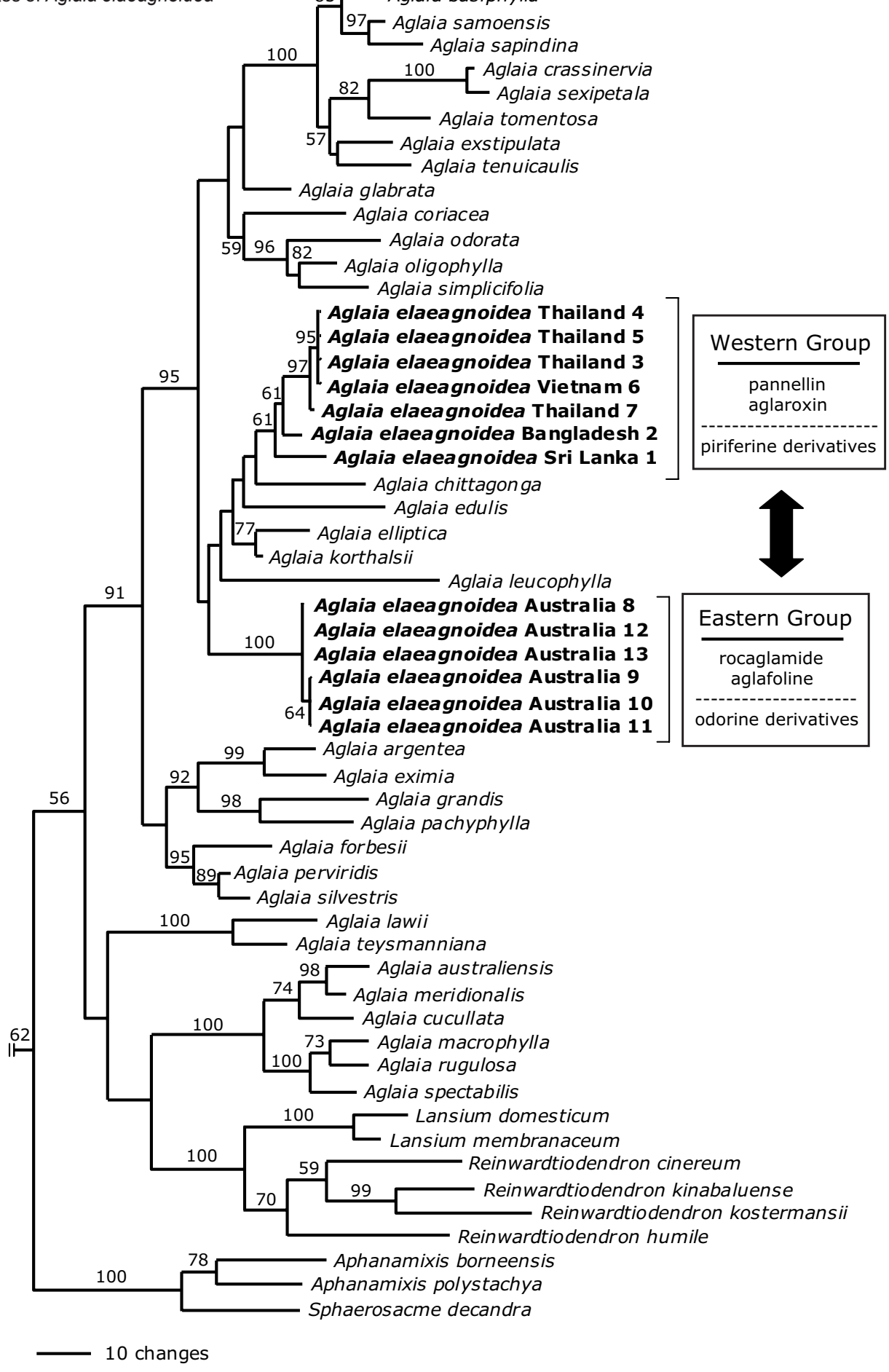

2. The clade comprising Guarea and Ruagea was constrained to minimally $23.03 \mathrm{Ma}$ (the upper bound of the Late Oligocene), based on fossil pollen of Guarea from the Oligocene San Sebastian Formation in northern Puerto Rico (Graham \& Jarzen 1969).

3. The crown group of Melieae was constrained to minimally $20.43 \mathrm{Ma}$ (the upper bound of the Aquitanian in the Early Miocene), based on fossil pollen of Melia (pollen similar to Melia azedarach) from the Early Miocene of Cameroon (Salard-Cheboldaeff 1978).

4. The clade comprising Chisocheton and the remainder of Guareae and Aglaieae was constrained to minimally 5.3 Ma (the upper bound of the Late Miocene), based on Miocene fossil wood of Chisocheton (Chisochetonoxylon) from the Birbhum District in West Bengal (Ghosh \& Roy 1979).
5. The stem of Cedreleae was constrained to minimally 48.6 $\mathrm{Ma}$ (the upper bound of the Early Eocene), based on fruit and seed fossils ascribed to Toona from the London Clay (Reid \& Chandler 1933, Chandler 1964). These specimens share morphological features of both modern Toona and Cedrela (T.D. Pennington, RBGK, pers. comm. 2005).

For absolute ages we relied on the geologic time scale of Gradstein et al. (2004).

\section{RESULTS}

We checked the ITS sequences for the presence of structural motifs and secondary structure. This enabled us to unambiguously align the entire ITS region across all genera (ingroup and 
outgroup), without losing any potentially informative characters for subsequent phylogenetic analyses. There was no indication for multiple copies of ITS in any individual included in our analysis, indicating no need to clone PCR products. Sequences of all ingroup and outgroup taxa contained the conserved angiosperm motifs in ITS1, 5.8S and ITS2 (Liu \& Schardl 1994, Hershkovitz \& Zimmer 1996, Jobes \& Thien 1997).

\section{Phylogeny estimation}

Alignment of all ITS region sequence positions resulted in a matrix of 803 characters for the whole set of taxa. The length of the total matrix including $18 \mathrm{~S}$ and $26 \mathrm{~S}$ rDNA flanking regions was 1010 characters. For the entire ITS region, 517 (64\%) positions were variable and 418 (52\%) were potentially parsimony informative. The parsimony search produced 288 most parsimonious trees of 2863 steps with a consistency index $(\mathrm{Cl})$ $=0.34$ and a retention index $(\mathrm{RI})=0.61$. Fig. 2 shows the strict consensus tree obtained from the MP analysis of 90 ingroup and four outgroup taxa, and bootstrap values. The Bayesian (Fig. 3) and ML (Fig. 4) analyses were all based on the same dataset as used for the MP analysis. The Bayesian tree was based on a total of 20000 trees and a burn-in of 910 trees (Fig. 3).

\section{Infra-specific polymorphism}

We included 13 accessions of the morphologically complex species Aglaia elaeagnoidea in our analyses, from two main areas beyond the western and eastern boundaries of Malesia. The samples exhibited high genetic diversity, topologically covering two portions of our phylogenetic trees (Fig. 3, 4). Accessions from western regions showed the following pattern: samples from Thailand and Vietnam formed a strongly supported clade in all trees (98\% bootstrap percentage, BP, Fig. 2; $100 \%$ posterior probability, PP, Fig. 3; 97 \% BP, Fig. 4), followed by a grade of samples from Bangladesh and Sri Lanka (Fig. 2-4); all western samples together formed a weakly to moderately supported clade (73\% BP, Fig. 2; 93 \% PP, Fig. 3; $61 \%$ BP, Fig. 4 ; in the following referred to as 'Western Group'). Accessions from eastern regions appeared in a strongly supported clade (100\% BP and PP, respectively, in all trees; in the following referred to as 'Eastern Group').

\section{Divergence time estimation}

Divergence time estimates for selected nodes are given in Fig. 3. Results based on NPRS and the Bayesian approach yielded similar age estimates. Age estimates derived from the Bayesian approach, based on several fossils, can be viewed as best approximations. Our Bayesian age estimates suggest that the clade of Aglaia samoensis and $A$. sapindina dates back to $5.7 \pm 3.7 \mathrm{Ma}$, the clade uniting samples of the Western Group to $11.7 \pm 4.8 \mathrm{Ma}$, the clade uniting samples of the Eastern Group to $5.3 \pm 3.5 \mathrm{Ma}$, and the clade of $A$. australiensis and A. meridionalis to $5.2 \pm 3.4 \mathrm{Ma}$ (Fig. 3).

\section{DISCUSSION}

Our study 1) provides the first assessment of the genetic diversity of Aglaia elaeagnoidea on the basis of a geographic sampling from the two ends of the distribution; 2) investigates the geographic structure of the data over the sampled geographic range; 3 ) evaluates the two ends of the morphological continuum which led to the wide species concept formerly adopted for $A$. elaeagnoidea; and 4) suggests that Australia has been colonized only recently by $A$. elaeagnoidea and other species. Our conclusions are based on several lines of evidence.

\section{Genetic diversity and geographic structure of Aglaia elaeagnoidea}

Aglaia elaeagnoidea is a widespread species, which occurs throughout the range of the genus except for the Solomon Islands and extends beyond the range of any other species in the genus in Western Australia. It appears to have two distinct entities at the eastern and western ends of its range, outside the Malesian area, linked by a series of morphological intermediates through Malesia. It was therefore considered to be a complex species by Pannell (1992). Unlike most species of Aglaia, it is not a rain forest tree, apparently adapted to a more seasonal climate. It is usually coastal, especially in the east of the range, but is also found inland and at higher elevations in India, Sri Lanka, Thailand and Borneo, on dry sandy soils and limestone.

On the basis of our geographic sampling strategy, specimens assigned to $A$. elaeagnoidea based on morphological grounds according to the current literature (Pannell 1992, 2004), appear as genetically heterogeneous (Fig. 2-4). Specimens to the far east and west of the range of the species belong to two different genetic entities based on ITS data.

\section{Taxonomic considerations - Aglaia elaeagnoidea and $A$. roxburghiana}

Historically, two main species were recognized in the Aglaia elaeagnoidea complex: $A$. elaeagnoidea (basionym Nemedra elaeagnoidea A.Juss. 1830) from Australia and A. roxburghiana (Wight \& Arn.) Miq. (basionym Milnea roxburghiana Wight \& Arn. 1834) from India and Sri Lanka. Various varieties and species names were applied to both of these to deal with the variation encountered within and between these two extremes in morphology and geographical range. In the monograph of Aglaia (Pannell 1992), it was treated as one widespread species, $A$. elaeagnoidea. It is usually a small tree or shrub, 5-10 $\mathrm{m}$ tall. The large pale orange or almost white peltate scales are characteristic, but they vary in colour, in the presences and extent of the fimbriate margin and in their density on the plant. In the eastern part of the range, the scales are larger, paler in colour and more frequently entire than in the west, the density is greater on the leaves, but the fruits may have fewer scales than in the west and the aril may be vestigial. In India, A. elaeagnoidea is sometimes a larger tree, to 20 $\mathrm{m}$, than in the rest of the range of the species. Large-leaved specimens from the west can also be almost indistinguishable from another complex species, $A$. edulis, unless fruits are present; these are much larger (up to $3.2 \times 3.8 \mathrm{~cm}$ ) in $A$. edulis than are those of $A$. elaeagnoidea (up to $2 \times 1.5 \mathrm{~cm}$ ) and usually 3-locular rather than 2-locular. The molecular data presented here confirm that the two extremes of variation in A. elaeagnoidea can be distinguished at the molecular level, just as they can on morphological characters. Interestingly, samples from Australia are not in the clade which separates most eastern species of section Aglaia from the rest of the genus (top clade in Fig. 2-4). The material of $A$. elaeagnoidea from Australia was collected from a relatively small area of Queensland and the samples are all similar at the molecular level for the DNA region sequenced. There is more variation in the samples from the west of the range, reflecting the larger area from which they were collected. Specimens from these two widely separated regions are distinct at the morphological and at the molecular level. On morphological and molecular evidence, the name Aglaia roxburghiana could be reinstated for specimens from the western end, but we have no data yet to indicate clearly where $A$. roxburghiana ends and $A$. elaeagnoidea begins either morphologically or geographically. This will be subject to further investigations. To reach a detailed appreciation of $A$. elaeag- 
noidea in addition to the patterns already elucidated by present evidence, sampling of additional specimens, especially from the Malesian region, will be necessary.

\section{Additional evidence derived from biogenetic trends - patterns of secondary metabolites in the Western versus Eastern Group of Aglaia elaeagnoidea}

Broad-based phytochemical comparisons with the 13 samples of Aglaia elaeagnoidea collected in various parts of Thailand, Vietnam, Bangladesh, Sri Lanka, and Australia showed chemical differences clearly separating all collections from Australia (Eastern Group) from the others (Western Group). Especially the genus-specific flavaglines of all representatives of the Eastern Group deviated by derivatives with a dimethoxylated aromatic ring $\mathrm{A}$, like rocaglamide and aglafoline, whereas all other collections from the west were characterized by a methylenedioxy and a methoxy group in ring $A$, like pannellin and aglaroxin A (Brem 2002, Hofer 2002). Additionally, the Australian samples were characterized by the formation of a triterpene derived limonoid, 6- $\alpha$-acetoxygedunin (Hofer 2002). Although widespread in the Meliaceae, limonoids are apparently rare in Aglaia, only described so far for another collection of $A$. elaeagnoidea from Sempu Island (Java) also containing the flavagline aglafoline with a dimethoxylated ring A (Fuzzati et al. 1996). The accumulation of different bisamides represents another important chemical character distinguishing the Australian samples from the Western Group. Whereas odorine derivatives are dominating in Australian collections, samples in the Western Group are characterized by piriferine derivatives. Both types of bisamides were also found as characteristic building blocks in the flavaglines (Greger et al. 2008). Different patterns of lignans and flavonoids may also contribute to a taxonomic segregation of the Eastern Group of $A$. elaeagnoidea (Hofer 2002, Greger unpubl.).

\section{Temporal origin of Western and Eastern Groups of Aglaia elaeagnoidea, and relatives}

Our results imply that the ancestor of the clade comprising the individuals of the Western Group currently assigned to Aglaia elaeagnoidea originated in the western part of the distribution range of the genus and of $A$. elaeagnoidea, respectively, subsequently dispersing eastwards. This pattern from west to east can be observed based on the topologies of the trees within the Western Group (Fig. 3, 4). These topologies suggest that earlybranching within $A$. elaeagnoidea occurred in western areas including Sri Lanka and Bangladesh. Aglaia elaeagnoidea then seems to have extended its range eastwards to areas including Thailand and Vietnam.

Based on the evidence of the tree topologies suggesting that the Western Group of $A$. elaeagnoidea originated in the very western part of the distribution range of the genus, we were interested in the relative timing of divergence events that had given rise to the western versus eastern clades of Aglaia species in our trees. If Aglaia had originated in the west, then clades comprising samples from Australia, as representatives of lineages from the east, should be comparably younger. Our divergence time estimates yielded estimates confirming these expectations (Fig. 3). Based on this measure, clades/groups with specimens collected in Australia (from species either restricted in their occurrence to Australia, like A. australiensis and $A$. meridionalis, or having a broader range of distribution, like $A$. sapindina; compare Fig. 3) date back to 5.2-5.7 Ma. The Eastern Group of $A$. elaeagnoidea dates back to minimally 5.3 mya. In contrast, the group comprising western $A$. elaeagnoidea dates back to minimally 11.7 mya. This suggests that old Gondwanan land masses like Australia might have been colonized only recently by $A$. elaeagnoidea and other species (compare Muellner et al. 2008a), with divergence events mostly dating back to the Miocene/Pliocene boundary and subsequent Pliocene times.

Acknowledgements We thank $\mathrm{H}$. Henselewski (Frankfurt) for help in the lab and an anonymous reviewer and P.C. van Welzen (Leiden) for their valuable comments. Financial support for this study was provided by the Marga and Kurt Moellgaard Fund (project no. T130/2390/2520/15159/07), the research funding programme 'LOEWE - Landes-Offensive zur Entwicklung Wissenschaftlich-ökonomischer Exzellenz' of Hesse's Ministry of Higher Education, Research, and the Arts, and the Senckenberg Research Institute, to A. Muellner.

\section{REFERENCES}

Brem B. 2002. Distribution and insecticidal properties of characteristic plant constituents from tropical Aglaia and Stemona species. PhD thesis, University of Vienna, Austria.

Brenner GJ. 1996. Evidence for the earliest stage of angiosperm pollen evolution: A paleoequatorial section from Israel. In: Taylor DW, Hickey LJ (eds), Flowering plant origin, evolution and phylogeny: 91-115. Chapman \& Hall, New York.

Chandler MEJ. 1964. The lower Tertiary floras of southern England. IV. A summary and survey of findings in the light of recent botanical observations. Bulletin of the British Museum (Natural History). Geology 12: 1-151, pl. 1-4.

Cowan RS, Chase MW, Kress J, Savolainen V. 2006. 300,000 species to identify: problems, progress, and prospects in DNA barcoding of land plants. Taxon 55: 611-616.

De Jussieu AHL. 1830. Nemedra elaeagnoidea A.Juss. Memoires du Museum d'Histoire Naturelle, Paris XIX: 223.

Felsenstein J. 1985. Confidence limits on phylogenetics: an approach using the bootstrap. Evolution 39: 783-791.

Fitch WM. 1971. Toward defining the course of evolution: minimal change for a specific tree topology. Systematic Zoology 20: 406-416.

Fuzzati N, Dyatmiko W, Rahman A, Achmad F, Hostettmann K. 1996. Triterpenoids, lignans and a benzofuran derivative from the bark of Aglaia elaeagnoidea. Phytochemistry 42: 1395-1398.

Ghosh PK, Roy SK. 1979. Chisochetonoxylon benegalensis gen. et sp. nov., a new fossil wood of Meliaceae from the Tertiary beds of Birbhum District, West Bengal, India. Current Science 48: 737-739.

Gradstein FM, Ogg JG, Smith AG. 2004. A geologic time scale 2004. Cambridge University Press, Cambridge, United Kingdom.

Graham A, Jarzen DM. 1969. Studies in Neotropical paleobotany. I. The Oligocene communities of Puerto Rico. Annals of the Missouri Botanical Garden 56: 308-357.

Greger H, Hofer M, Teichmann K, Schinnerl J, Pannell CM, Vajrodaya S, Hofer O. 2008. Amide-esters from Aglaia tenuicaulis - first representatives of a class of compounds structurally related to bisamides and flavaglines. Phytochemistry 69: 928-938.

Hershkovitz MA, Zimmer EA. 1996. Conservation patterns in angiosperm rDNA ITS2 sequences. Nucleic Acids Research 24: 2857-2867.

Hofer M. 2002. Infraspezifische chemische Differenzierung am Beispiel von asiatischen und australischen Herkünften von Aglaia elaeagnoidea (Meliaceae). Master Thesis, University of Vienna.

Hughes NF. 1994. The enigma of angiosperm origins. Cambridge palaeobiology series 1. Cambridge University Press, Cambridge.

Jobes DV, Thien LB. 1997. A conserved motif in the 5.8S ribosomal RNA (rRNA) gene is a useful diagnostic marker for plant internal transcribed spacer (ITS) sequences. Plant Molecular Biology Reporter 15: 326-334.

Liu J-S, Schardl CL. 1994. A conserved sequence in internal transcribed spacer 1 of plant nuclear rRNA genes. PI. Molec. Biol. 26: 775-778.

Mathews DH, Sabina J, Zuker M, Turner DH. 1999. Expanded sequence dependence of thermodynamic parameters improves prediction of RNA secondary structure. Journal of Molecular Biology 288: 911-940.

Muellner AN. 2008. Genetic diversity and distribution patterns of Aglaieae (Meliaceae) in Malesia. Flora Malesiana Bulletin 14: 198-201.

Muellner AN, Pannell CM, Coleman A, Chase MW. 2008a. The origin and evolution of Indomalesian, Australasian and Pacific island biotas: insights from Aglaieae (Meliaceae, Sapindales). Journal of Biogeography 35: 1769-1789.

Muellner AN, Samuel R, Chase MW, Coleman A, Stuessy TF. 2008b. An evaluation of tribes and generic relationships in Melioideae (Meliaceae) based on nuclear ITS ribosomal DNA. Taxon 57: 1-11.

Muellner AN, Samuel R, Chase MW, Pannell CM, Greger H. 2005. Aglaia (Meliaceae): an evaluation of taxonomic concepts based on DNA data and secondary metabolites. American Journal of Botany 92: 534-543. 
Muellner AN, Samuel R, Johnson SA, Cheek M, Pennington TD, Chase MW. 2003. Molecular phylogenetics of Meliaceae based on nuclear and plastid DNA sequences. American Journal of Botany 90: 471-480.

Muellner AN, Savolainen V, Samuel R, Chase MW. 2006. The mahogany family 'out-of-Africa': divergence time estimation, global biogeographic patterns inferred from plastid rbcL DNA sequences, extant, and fossil distribution of diversity. Molecular Phylogenetics and Evolution 40: 236-250.

Muellner AN, Vassiliades DD, Renner SS. 2007. Placing Biebersteiniaceae, a herbaceous clade of Sapindales, in a temporal and geographic context. Plant Systematics and Evolution 266: 233-252.

Pannell CM. 1992. A taxonomic monograph of the genus Aglaia Lour. (Meliaceae). Kew Bulletin Additional Series XVI. HMSO, London, United Kingdom.

Pannell CM. 1993. A monograph of Aglaia (Meliaceae) - a correction. Kew Bulletin 48: 244.

Pannell CM. 1995. Aglaia. In: Mabberley DJ, Pannell CM, Sing AM (eds), Meliaceae. Flora Malesiana, Ser. I, Vol. 12: 194-314.

Pannell CM. 1998a. Taxonomy, ecology and reproductive biology of Aglaia (Meliaceae). In: Hopkins HCF, Huxley CR, Pannell CM, Prance GT, White $\mathrm{F}$ (eds), The biological monograph: The importance of field studies and functional syndromes for taxonomy and evolution of tropical plants, A Festschrift for Frank White: 59-77. Royal Botanic Gardens Kew, London, United Kingdom.

Pannell CM. 1998b. Species delimitation in Aglaia. In: Hopkins HCF, Huxley CR, Pannell CM, Prance GT, White F (eds), The biological monograph, The importance of field studies and functional syndromes for taxonomy and evolution of tropical plants, A Festschrift for Frank White: 124-127. Royal Botanic Gardens Kew, London, United Kingdom.

Pannell CM. 2004. Three new species, two new subspecies and five new combinations at the subspecific level in Aglaia Lour. (Meliaceae). Kew Bulletin 59: 87-94.

Posada D, Crandall KA. 1998. Modeltest: testing the model of DNA substitution. Bioinformatics 14: 817-818.

Rambaut A, Charleston M. 2000. Phylogenetic Tree Editor v1.0 alpha 4-61. http://evolve.zoo.ox.ac.uk/software/TreeEdit. Updated version currently available at http://tree.bio.ed.ac.uk/software/treeedit/.
Reid EM, Chandler MEJ. 1933. The London Clay Flora. British Museum (Natural History), London, United Kingdom.

Ronquist F, Huelsenbeck JP. 2003. MrBayes 3: Bayesian phylogenetic inference under mixed models. Bioinformatics 19: 1572-1574.

Salard-Cheboldaeff M. 1978. Sur la palynoflore Maestrichtienne et Tertiaire du basin sédimentaire littoral du Cameroun. Pollen and Spores 20: 215 260.

Sanderson MJ. 1997. A nonparametric approach to estimating divergence times in the absence of rate constancy. Molecular Biology and Evolution 14: $1218-1232$.

Stamatakis A. 2006. RAxML-VI-HPC: Maximum likelihood-based phylogenetic analyses with thousands of taxa and mixed models. Bioinformatics 22: $2688-2690$

Swofford DL. 2002. PAUP*: phylogenetic analysis using parsimony ("and other methods), v4. Sinauer Associates, Sunderland, Massachusetts, USA. Thompson JD, Gibson TJ, Plewniak F, Jeanmougin F, Higgins DG. 1997. The ClustalX windows interface: flexible strategies for multiple sequence alignment aided by quality analysis tools. Nucleic Acids Research 24: 4876-4882.

Thorne JL, Kishino H. 2002. Divergence time estimation and rate evolution with multilocus data sets. Systematic Biology 51: 689-702.

Thorne JL, Kishino H, Painter IS. 1998. Estimating the rate of evolution of the rate of molecular evolution. Molecular Biology and Evolution 15: 1647-1657.

Wight RA, Walker GA. 1834. Milnea roxburghiana Wight \& Arn. Prodromus Florae Peninsulae Indiae Orientalis 1: 119.

Yang Z. 1997. PAML: a program package for phylogenetic analysis by maximum likelihood. Computer Applications in BioSciences 13: 555-556 (http://abacus.gene.ucl.ac.uk/software/paml.html).

Zuker M, Mathews DH, Turner DH. 1999. Algorithms and thermodynamics for RNA secondary structure prediction: a practical guide. In: Barciszewski J, Clark BFC (eds), RNA biochemistry and biotechnology, 11-43. NATO ASI Series. Kluwer Academic Publishers, Dordrecht, Netherlands. 